\title{
41
}

\section{By Way of Conclusion: Future Research}

\author{
Frank Nullmeier, Delia González de Reufels, \\ and Herbert Obinger
}

\begin{abstract}
A book project such as the present one cannot close without attempting to take a tentative glimpse at research in the field this collection of contributions is dedicated to. In this volume, the authors have highlighted the inter- and transnational interdependencies of national social policies through a series of individual stories that aspire to add to a more complex and comprehensive picture of how the national and the global come together. We have named these stories short histories because they show the interplay of international developments and national policies for single countries, for specific policy fields within the welfare state, and for certain periods of time. As a matter of fact, the list of conceivable short histories could be easily extended to cover more regions, more specific points in history and policies. Of course, there are many journal articles, edited volumes and books available that address and also explain in greater detail specific interdependencies and their effects on social policy.
\end{abstract}

F. Nullmeier $\bullet$ D. G. de Reufels $(\bowtie) \bullet$ H. Obinger

University of Bremen, Bremen, Germany

e-mail: frank.nullmeier@zes.uni-bremen.de; dgr@uni-bremen.de;

herbert.obinger@uni-bremen.de 
Yet, the volume at hand seeks to show how this kaleidoscope of short essays adds to comparative social policy research, and just like research on global social policy, will thus be able to provide more and more detailed knowledge about more and more social policy fields, countries and historical periods. Thus, social policy in the Global South will no longer be a blank space. Furthermore, knowledge about development trends beyond the Western countries can reach such a density and breadth that existing deficits and one-sidedness can gradually be overcome. The accumulation of many individual findings favours a tendency to focus on distinct historical processes as well as national contexts and to emphasise particularities. This makes it difficult, however, to obtain an overall picture of historical developments across countries and regions, across policy fields and across epochs. Far from writing a new and now global history of social policy, research can even fragment into a multitude of specialised fields and separate insights.

Instead, it would be highly desirable if the history of the interdependencies of social policies could be told more comprehensively and systematically — even though a Grand Narrative may not be needed. Instead, it is of great interest to analyse the relative importance of the four groups of interdependencies distinguished here. These raise a number of questions that still need to be answered: When and where do linkages or overlaps occur between these forms of interdependence? Are there typical forms of response to war and violence in social policy that are fundamentally different from reactions to economic crises, high immigration or ideational influence from international organisations? Or are there parallel developments in social policy for the various forms of interdependence? In the case of interdependence between North and South, are national social policies complementary to each other? And are there different national development paths for all forms of interdependence despite similar exposure to the respective transnational influence?

All of this can neither be answered on the basis of the existing literature nor by the short histories presented here. Further efforts are needed to achieve the quality of a global history of social policy or globally and historically based social policy research with a systematic explanatory claim. Possible ways of more closely interrelating the results of research 
need to be explored. How this can be achieved is a question of both the format of scientific publications and of the design of scientific research.

Handbooks have been established in the last two decades as the central format for the summarised presentation of the state of research in a thematic area. Due to their size, with twenty-five to forty-five individual chapters, they enable the state-of-the-art in research to be presented with the involvement of a large number of leading researchers, each of whom can summarise his or her specific field (i.e. Castles et al. 2010; Greve 2013; Leibfried et al. 2015; Midgley et al. 2019; Béland et al. 2021). By revising and reprinting within appropriate time spans (between five and ten years), a sum of research can be given at the most up-to-date level. However, detailed accounts of individual historical events are not part of the scope of these handbooks which offer information on individual research projects instead, and remain at the level of a summary of the current state of research.

By contrast, encyclopaedias as print products but also as digital initiatives have rather faded into the background. The possibility of an approach to the global history of social policy that is topic-specific, made manageable by a lexical structure, in other words, "Health Policy Tanzania" or "Accident Insurance Germany" with sub-chapters that map the individual historical phases, has not yet been explored. This would resemble a Wikipedia approach that necessarily would have to be the collective effort of the scientific community. The structure of the outline mentioned, serves here only as an example of how this would fixate on nominal subfields of social policy and the level of nation states. The basic structure of such a volume can also be extended by adding other categories such as specific actors and institutions in order to provide a certain counterweight to the concentration on sub-policies and nation states. Whether this or a fundamentally different categorisation would be desirable, needs to be clarified in advance. And even if such questions could be broadly agreed upon at the international level and the organisational prerequisites of such a huge undertaking were clarified, the project would remain essentially committed to a descriptive account of social policy development. Even though such an approach could provide individual explanations for subfields and states, it nevertheless would be 
overstretched with the task of a comparative and integrated explanation of social policy developments.

Certainly, there is also the possibility of a large, comprehensive monograph or of edited volumes involving only a few authors, a format that is already well established and even quite characteristic for publications in the field of global history. But then, historians are usually in a better position to do this and have for a long time transferred the tradition of comprehensive national history into equally comprehensive global histories covering complete centuries (Bayly 2004; Iriye and Osterhammel 2012; Osterhammel 2014). For political science and sociology, the undertaking of portraying entire historical epochs across countries for all significant fields of social policy is a highly unusual challenge, even if there are approaches to this form of portrayal. These cover entire continents, but with a rather lower level of detail per country, field of social policy and historical phase (i.e. Haggard and Kaufman 2008; Huber and Stephens 2012). In a monographic form, the potential to use a unified explanatory approach is certainly given, but then it all depends on the ability of individual authors to compile research results.

Thus, the format of publication alone is most likely not able to shoulder the burden in question and offer a solution as to how further research can proceed in a more systematic and integrated way. In fact, what matters most is the design of the research.

A highly successful form of focusing social policy research has been achieved through the introduction of types and typologies. EspingAndersen's The Three Worlds of Welfare Capitalism (1990) still has the capacity, even after thirty years, to stimulate or even pre-structure new research projects and thinking about new social policy developments. No sampling decision can get beyond his typology, and new typological attempts present themselves as extensions or modifications of his threefold typology. Even if it is noted that classifying a country into a certain type is not really accurate, Esping-Andersen's typological distinction still organises the further development of research on this case. This formative power has also stimulated typological attempts that referred specifically to the Global South (Wood and Gough 2006; Seekings 2008; Roumpakis and Sumarto 2020; Carvalho et al. 2020). However, the latter in particular has not really succeeded so far. The typological attempts beyond the 
OECD_Organisation for Economic Co-operation and Developmentcountries are at odds with Esping-Andersen's attempt at classification and cannot be linked to each other. Building typologies as a specific result of comparative social policy research has been highly effective for a limited group of countries, but this has not had even a remotely organising effect for social policy research on a global scale. The effectiveness for OECD countries is due to the fact that a typology based on the decommodification approach presupposes a basic logic of social policy centred on paid employment and a large sector of formal work. However, this prerequisite is not given in a large number of countries which nevertheless have social policy programmes. The empirical research has been stimulated by typologies and classification debates, which in turn initiated a closer examination of subfields of social policy (Aspalter 2019). However, such a classification debate will seem irrelevant when it becomes apparent that the respective social policy conditions clearly deviate from the model descriptions for a type. It is then better to turn to the individual case in its specificity.

Regardless of their success or failure in research practice, typologies have their own weaknesses: They are comparatively static. The boundary lines drawn between types tend to make it more difficult to understand dynamics, since a distinction must always be made between changes within a type and changes that have a type-changing effect, which tends to overlook gradual change or hybridisation. Finally, it remains unclear what explanatory value such typologies can have. Do they only serve to describe or do the types simultaneously include a complex combination of factors that can gain explanatory power?

A second way of organising research, which was designed from the very beginning to provide explanations, is via the competition of theoretical approaches. Originally, these theoretical approaches were conceived as mutually exclusive candidates for explaining social policy in general. The socio-economic approach extended modernisation theory to the field of social policy, while the power resource approach responded with a Marxist-inspired conceptualisation. With the party-matters approach and the institutionalist approaches, more policy-centred theories emerged, claiming to explain social policy as a whole. Over time, however, this claim to exclusivity gave way, especially under the influence of 
macro-quantitative comparative research, to an arrangement in which the explanatory variables central to the respective theoretical approach were integrated into a multifactorial research framework. Today, the theories stand side by side rather than opposite each other, because every attempt to explain certain elements of social policy results in the primacy of a different set of variables, so that there are always cases in which one or the other explanatory approach proves to be accurate. The lack of appropriately comprehensive datasets has slowed down the extension of this research approach to the countries of the Global South, but has not changed the arrangement of presenting explanations as a specific combination of a set of factors that were originally designed as alternatives. The literature on the diffusion of ideas, concepts and instruments of social policy from one country or International Organisation to another country, which is much more oriented towards the countries of the Global South and the role of international organisations, operated in a similar way. What could have been a general explanation for diffusion-emulation or learning, or competition or coercion-was very quickly used for explanations showing that in one specific case this, in another case that diffusion pathway came into effect. All diffusion pathways, however, were quickly rejected as universal theories. Transnational interdependencies are just another factor in this framework. This weakening of the competition between theories for the investigation of factor combinations hardly allows for theory building with a general claim to explanation, while it also reduces the value of individual studies for more comprehensive questions. In the end, comparative studies, which certainly include a larger number of countries, become a variant of single case studies.

A prerequisite for variable-based research is the availability of corresponding data on the relevant variables for as large a number of countries as possible. Systematically expanding the database and merging existing data in a data portal is therefore a key way to enable more systematic research. Initially, the work on data collection is essentially descriptive, but it is this compilation of data that makes explanatory work possible. The laborious work of cross-checking data and identifying the level of evidence that can be attributed to certain data is still too little valued in science. Databases are encyclopaedias in a schematised form. If data 
collection and processing are successful, data portals bring research together worldwide and form a focal point of interrelated research work.

Classification of transnational interdependencies using the larger number of explanatory factors can certainly relativise an exuberant transnationalism, but the specific significance of the interdependencies can hardly be elaborated in this way. Therefore, to conduct research that transcends national borders from the outset, in other words, starts from interdependencies and shows their different effectiveness on social policy in different national contexts, could be a road to follow. This has been achieved in exemplary fashion-albeit beyond social policy research-in Sven Beckert's Empire of Cotton. A Global History (2014). In a similar way, the effects of labour migration or the significance of individual industries integrated into the world market, such as mining, could serve as starting points. The studies by Obinger et al. (2018) on mass warfare are already on the way to such an analysis based on interdependencies. Something similar could be developed for comparably disruptive events such as economic crises and situations of upheaval, or the collapse of the Soviet Union and its consequences.

The approach sketched out here could furthermore be combined with the search for causal mechanisms that have either promoted the expansion or the dismantling of social policy. The concept of causal mechanisms can be used to analyse questions of social policy research in greater detail than has been possible with the common approaches to this research area. The conceptual advantage of causal mechanisms is that they provide the basis for a decomposed form of comparison at sub-levels of political processes, since processes can be broken down into smaller units and these sequences can be studied in a far more differentiated manner, without having to assume that the overall analysis would have to be integrated into a specific approach afterwards (Kuhlmann and Nullmeier 2021). This level can then be used as a reference for comparisons. A causal mechanism approach thus allows for an analytically pre-structured method for (single) case studies that is oriented towards comparisons of sequences. The use of causal mechanisms is a route to detect patterns and identify regularities, but not at the level of political systems, regimes, structures, policy fields or entire process cycles. Rather, mechanisms allow for the detection of smaller regularities at the level of sequences, which can be observed in 
political processes at different times, places and topics. These kinds of regularities enable more than just descriptive access to the dynamics of a political process. Explanations are made in a modular way as a combination of the interplay of different causal mechanisms. In Warfare and Welfare, Obinger et al. describe a set of mechanisms that explain social policy expansion in the context of war, thereby distinguishing the phases of war preparation, mobilisation and the post-war period (for an overview see Obinger et al. 2018, 11-12). And in The Global Rise of Social Cash Transfers, Leisering (2019) introduces the mechanisms of "cultural linkages", "theorisation" and "quantification" as three mechanisms of global social policy diffusion. We assume that there is great potential for social policy research in continuing such efforts, especially as they allow for comparisons between case studies of historically widely divergent situations, different fields of social policy and very different countries not just from the Global North.

In sum, these formats and designs of research are not mutually exclusive alternatives. All of the aforementioned avenues can be followed in parallel and they will certainly contribute to enabling more interrelated and more systematic research. A plurality of approaches is therefore recommendable. However, in view of limited resources, it can also be helpful to advance some of these projects in a worldwide cooperation that at the same time preserves the research interests of all participants. Whatever formats and research designs enable us to identify the basic processes of social policy development and help us to understand how the different levels relate to each other, is an important step for future research.

\section{References}

Aspalter, Christian. 2019. Welfare Regime Analysis: 30 Years in the Making. International Social Work 62 (1): 76-88.

Bayly, Christopher A. 2004. The Birth of the Modern World, 1780-1914, Global

Connections and Comparisons. Oxford: Blackwell Publishing.

Beckert, Sven. 2014. Empire of Cotton. A Global History. New York: Alfred A. Knopf. 
Béland, Daniel, Kimberly Morgan, Herbert Obinger, and Christopher Pierson, eds. 2021. The Oxford Handbook of the Welfare State. 2nd ed. Oxford: Oxford University Press.

Carvalho, Gabriela de, Achim Schmid, and Johanna Fischer. 2020. Classifications of Health Care Systems: Do Existing Typologies Reflect the Particularities of the Global South? Global Social Policy. https://doi. org/10.1177/1468018120969315.

Castles, Francis C., Stephan Leibfried, Jane Lewis, Herbert Obinger, and Christopher Pierson, eds. 2010. The Oxford Handbook of the Welfare State. Oxford: Oxford University Press.

Esping-Andersen, Gøsta. 1990. The Three Worlds of Welfare Capitalism. Cambridge: Polity.

Greve, Bent, ed. 2013. The Routledge Handbook of the Welfare State. London and New York: Routledge.

Haggard, Stephan, and Robert R. Kaufman. 2008. Development, Democracy, and Welfare States: Latin America, East Asia, and Eastern Europe. Princeton, NJ: Princeton University Press.

Huber, Evelyne, and John D. Stephens. 2012. Democracy and the Left. Social Policy and Inequality in Latin America. Chicago and London: The University of Chicago Press.

Iriye, Akira, and Jürgen Osterhammel, eds. 2012. Geschichte der Welt, 1870-1945, Weltmärkte und Weltkriege. München: Beck.

Kuhlmann, Johanna, and Frank Nullmeier, eds. 2021. Causal Mechanisms in the Global Development of Social Policies. Cham: Palgrave Macmillan.

Leibfried, Stephan, Evelyne Huber, Matthew Lange, Jonah D. Levy, Frank Nullmeier, and John D. Stephens, eds. 2015. The Oxford Handbook of Transformations of the State. Oxford: Oxford University Press.

Leisering, Lutz. 2019. The Global Rise of Social Cash Transfers. How States and International Organizations Constructed a New Instrument for Combating Poverty. Oxford: Oxford University Press.

Midgley, James, Rebecca Surender, and Laura Alfers, eds. 2019. Handbook of Social Policy and Development. Cheltenham, UK; Northampton, MA: Edward Elgar.

Obinger, Herbert, Klaus Petersen, and Peter Starke. 2018. Introduction. Studying the Warfare-Welfare Nexus. In Warfare and Welfare: Military Conflict and Welfare State Development in Western Countries, ed. Herbert Obinger, Klaus Petersen, and Peter Starke, 1-35. Oxford: Oxford University Press. 
Osterhammel, Jürgen. 2014. The Transformation of the World. A Global History of the Nineteenth Century. Princeton, NJ: Princeton University Press.

Roumpakis, Antonios, and Mulyadi Sumarto. 2020. Introduction: Global Welfare Regimes Revisited. Journal Social Policy and Society 19 (4): 585-588. Seekings, Jeremy. 2008. Welfare Regimes and Redistribution in the South. In Divide and Deal: The Politics of Distribution in Democracies, ed. Ian Shapiro, Peter A. Swenson, and Daniela Donno Panayides, 19-42. New York: New York University Press.

Wood, Geof, and Ian Gough. 2006. A Comparative Welfare Regime Approach to Global Social Policy. World Development 34 (10): 1696-1712.

Open Access This chapter is licensed under the terms of the Creative Commons Attribution 4.0 International License (http://creativecommons.org/ licenses/by/4.0/), which permits use, sharing, adaptation, distribution and reproduction in any medium or format, as long as you give appropriate credit to the original author(s) and the source, provide a link to the Creative Commons licence and indicate if changes were made.

The images or other third party material in this chapter are included in the chapter's Creative Commons licence, unless indicated otherwise in a credit line to the material. If material is not included in the chapter's Creative Commons licence and your intended use is not permitted by statutory regulation or exceeds the permitted use, you will need to obtain permission directly from the copyright holder.

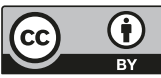

